\title{
Hydranencephaly: Considering Prolonged Survival and Treatment by Endoscopic Choroid Plexus Coagulation
}

\section{Hidranensefali: Endoskopik Koroid Pleksus Koagülasyonu Yoluyla Sağkalım Uzatılması ve Tedavinin Değerlendirilmesi}

Coby RAY, James MOBLEY, Mark THOMPSON, Laszlo NAGY

Texas Tech University Health Sciences Center, Department of Pediatric Neurosurgery, Lubbock/Texas, USA

Corresponding Author: Coby RAY / E-mail: coby.ray@ttuhsc.edu

\begin{abstract}
Arachnoid collapse is a previously unreported complication of endoscopic choroid plexus coagulation (ECPC) treatment of hydranencephaly and is demonstrated in this case report. The variable anatomy found in hydranencephaly supports the use of ECPC as the preferred treatment option. However, the same anatomical anomalies predispose the procedure to this unique complication. A brief literature review of hydranencephaly has also been performed and is reported through the discussion. Neurosurgeons must be aware of this very dangerous complication and a discussion of preventative measures are made. The use of ECPC and the clinical expectations of treating patients with hydranencephaly is also discussed.
\end{abstract}

KEYWORDS: Arachnoid collapse, Choroid plexus, Endoscopic choroid plexus coagulation, Hydranencephaly, Neuroendoscopy

Öz

Araknoid kolaps, hidrosefalinin endoskopik koroid pleksus koagülasyonu (ECPC) ile tedavisinin daha önce bildirilmemiş bir komplikasyonudur ve bu olgu raporunda bildirilmektedir. Hidranensefalideki değişken anatomi, tercih edilen tedavi seçeneği olarak ECPC kullanımını desteklemektedir. Ancak aynı anatomik anomaliler işlem sırasında sözkonusu komplikasyon açısından bir yatkınlık oluşturmaktadır. Hidranensefali için kısa bir literatür derlemesi yapılmıştır ve tartışmada verilmektedir. Beyin ve sinir cerrahlarının bu çok tehlikeli komplikasyondan haberdar olması gerekir ve önlemler tartışılmıştır. Hidranensefali hastaların tedavisinde ECPC kullanımı ve klinik beklentiler de açıklanmaktadır.

ANAHTAR SÖZCÜKLER: Araknoid kollaps, Koroid pleksus, Endoskopik koroid pleksus koagülasyonu, Hidranensefali, Nöroendoskopi

\section{INTRODUCTION}

An uncommon, but not unseen disease entity in the neonatal intensive care unit is the neurological congenital malformation of hydranencephaly. Hydranencephaly is a malformation of the central nervous system that results from errors of embryonic development post-neuralation (5). It has been proposed that the embryonic occlusion of the carotid arteries is the probable etiology of the disease based on the finding that only those structures supplied by posterior cerebral arteries form (3). The major and defining characteristics of hydranencephaly include an almost or complete lack of cortical mantle, specifically the cerebral hemispheres $(3,5,8)$. It is generally accepted that in hydranencephaly, if there is any remaining cortex present, it will not be functioning $(6,9)$. While the cerebral hemispheres are missing, this disease presents with the cranium and meninges completely intact $(5,8)$. Hydranencephaly is also characterized by the presence of varying degrees of brainstem, thalamus, hypothalamus, and cerebellum $(3,5,8)$. In addition to these findings there are no other facial or cranial abnormalities consistently associated with this disease. In fact this can be a very important clinical feature used in diagnosing this disease, (6) specifically in differentiating it from other congenital malformations, most importantly from severe hydrocephalus which presents with small cortical mantle (2).

A search of the literature reveals that there have been no large-scale studies on the life expectancy of infants with hydranencephaly. The current medical texts and limited literature seem to point to a general consensus that there is a significantly reduced life expectancy of individuals with hydranencephaly - mostly due to stillbirths or death within a few weeks of birth $(5,6,8)$. Malheiros, et al. also reported that those infants who survive the first few weeks of life still have a very poor prognosis and often die early from various complications, including pneumonia (5). While this has not been disproven as the norm, there are multiple case reports of exceptions to this prognosis, perhaps implying a more common possibility of increased life expectancies. McAbee, et al. reports two cases of prolonged survival in hydranencephaly, patients of twenty-four and sixty-six 
months (6). The literature review also described that while survival can occur up to nineteen years of age, there is no improvement in neurological condition (6). This lack of improved neurological status leads to the ethical dilemmas that often confound treatment decision-making for both the physicians and families. It is important to note that the possibility of prolonged life correlates well with the anatomy associated with the disease. The fact that prolonged survival is possible confirms that as McAbee, et al. reported "the circuits necessary for maintenance of temperature, blood pressure, and cardiorespiratory functions are, at least in part, functional in prolonged survivors" (6).

This case report will examine two very important facets of the rare disease process of hydranencephaly - survival potential and treatment via endoscopic choroid plexus coagulation (ECPC). The case presented demonstrates a previously unreported complication of ECPC - arachnoid collapse. The anatomical anomalies found in hydranencephaly do support the use of ECPC yet at the same time predispose the procedure to this unique complication. A qualitative literature review of hydranencephaly has also been performed and is reported through this discussion. The goal of this report is to provide neurosurgeons with the awareness of a complication to ECPC that they likely have never encountered, as well as discuss the use of ECPC and the clinical expectations of treating patients with hydranencephaly.

\section{CASE REPORT}

This patient was born full-term by cesarean section. The pregnancy was complicated by gestational diabetes and obesity. Of note, the mother's prenatal treatment included insulin. A diagnosis of hydranencephaly was made on a prenatal ultrasound. The neurosurgery team was consulted by the NICU staff and the patient was found to have severe macrocephaly (FOC of $52 \mathrm{~cm}$ ), dilated veins, sunset sign, bulging fontanel with sutural diastasis, palpable spine deformity of hemi-vertebra, and costal anomalies. A CT scan of the head showed evidence of a Chiari Malformation. A CT scan of the spine showed hemi-vertebra. Other studies revealed two undescended testes in the inguinal canals, a slightly enlarged heart, an atrial septal defect, ventricular septal defect, aortic stenosis, truncus arteriosus, quadricuspid aortic valve, and bilateral infiltrates in the lungs. A portable head ultrasound through the anterior fontanel revealed a large cystic area with a thin rim of cerebral parenchyma and that the thalami and basal ganglia were partially fused (Figure $1,2)$. These findings were confirmed with magnetic resonance imaging (Figures 3-5).

Approximately twelve hours prior to being taken for surgery, a transfontanel tap was performed until the fontanel was soft. The patient tolerated this procedure and no complications were noted. The patient was taken to the operating room for endoscopic coagulation of the choroid plexus. The patient was prone with the head of bed raised approximately 20 degrees above horizontal. Upon opening the layers a distinct skin, thin periosteal layer, and dura was observed (without the presence of bone). Through the dura a typically appearing large subdural fluid collection was observed. Two sutures were placed with 4-0 nurolon to secure the arachnoid layer to the dura to prevent collapse of the arachnoid. After this the dura and arachnoid were incised and the endoscope was inserted. (Figure 6) Irrigation of lactated ringer solution

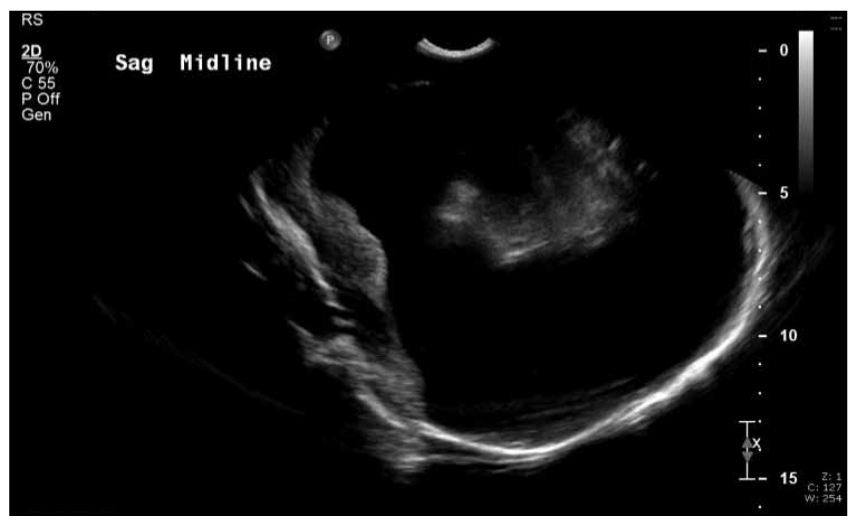

Figure 1: Sagittal midline ultrasound demonstrating the intact arachnoid preoperatively.

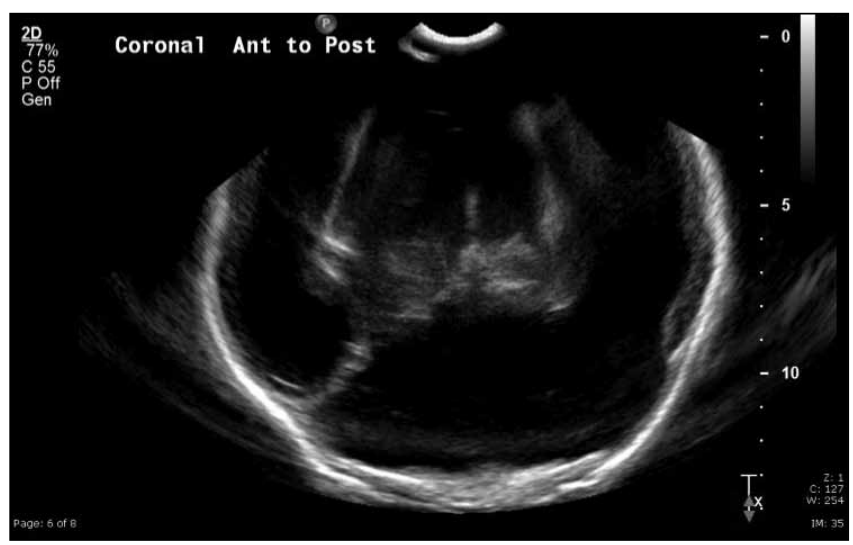

Figure 2: Coronal anterior to posterior ultrasound demonstrating the intact arachnoid preoperatively.

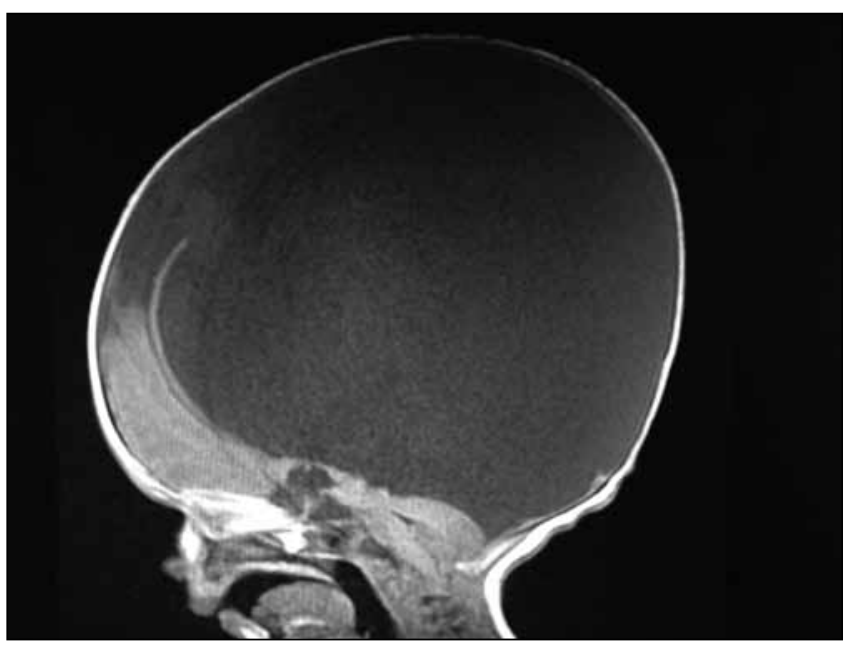

Figure 3: Sagittal T1 weighted MRI demonstrating hydranencephaly, pre-operative image. 
at body temperature was flowing. The right choroid plexus was identified and coagulated using electro-cautery. Upon slightly withdrawing the endoscope to gain an angle to visualize the left choroid plexus, the endoscopic view became very dark despite a functioning light. By visualizing the endoscope with loupes, it was apparent that the arachnoid layer was lying on the endoscope. At this point the arachnoid edges began bleeding and could not be controlled with the endoscope, so the endoscopic approach was abandoned and a microscope was utilized. Hemostasis was obtained with the use of the microscope. The procedure was completed with the microscope, including coagulation of a portion of the left choroid plexus and then it was tried unsuccessfully to clean the edges of the arachnoid. After the cranium was filled with lactated ringers solution, the incision was closed and

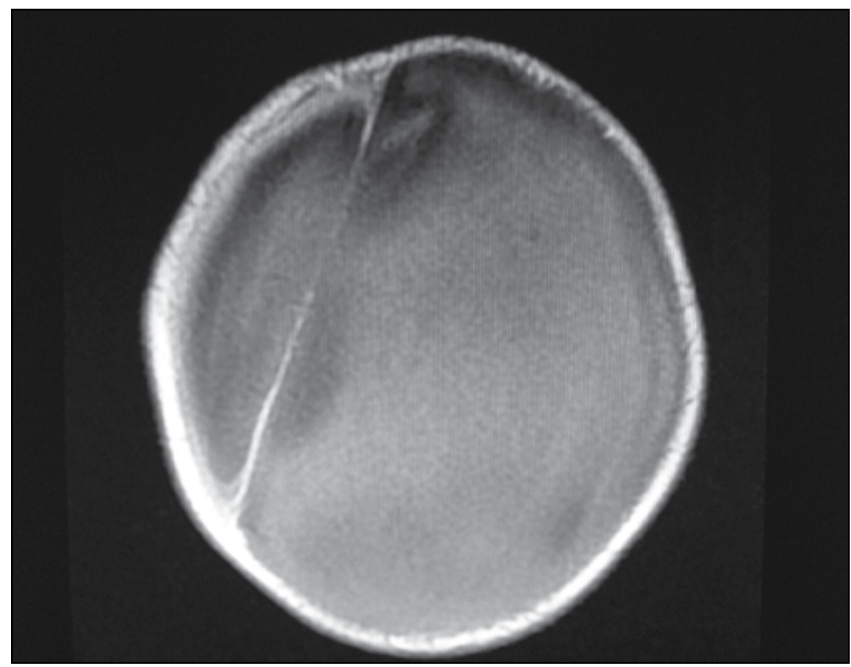

Figure 4: AxialT1 weighted MRI demonstrating hydranencephaly, pre-operative image.

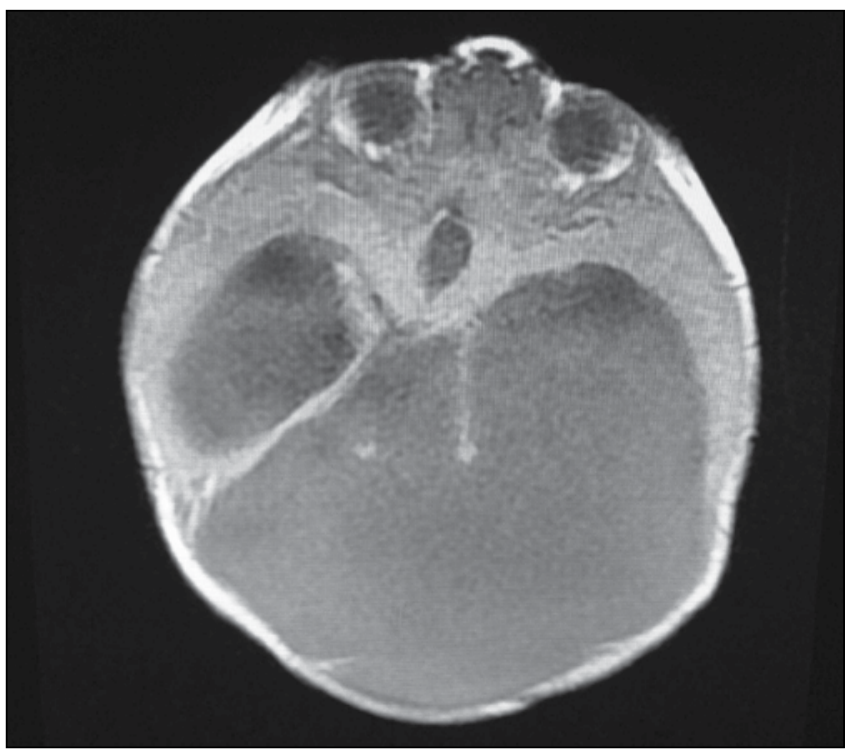

Figure 5: AxialT1 weighted MRI demonstrating hydranencephaly, pre-operative image. a reservoir was placed to the large fluid filled cavity. A postoperative ultrasound clearly demonstrated the collapsed arachnoid (Figure 7, 8). Approximately one month later the infant died of cardiogenic shock related to his heart anomalies.

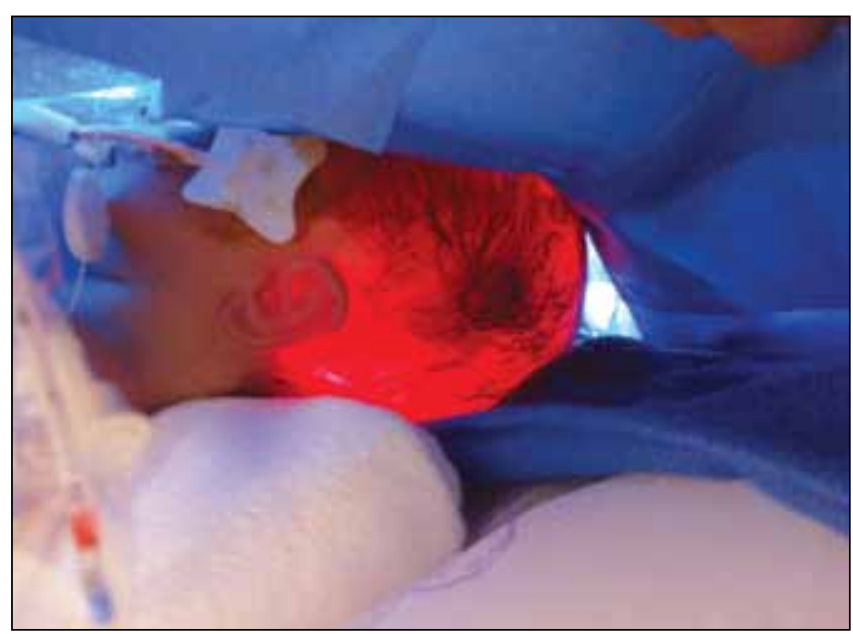

Figure 6: Intraoperative image taken by anesthesiologist showing illumination of the head due to the lack of brain parenchyma.

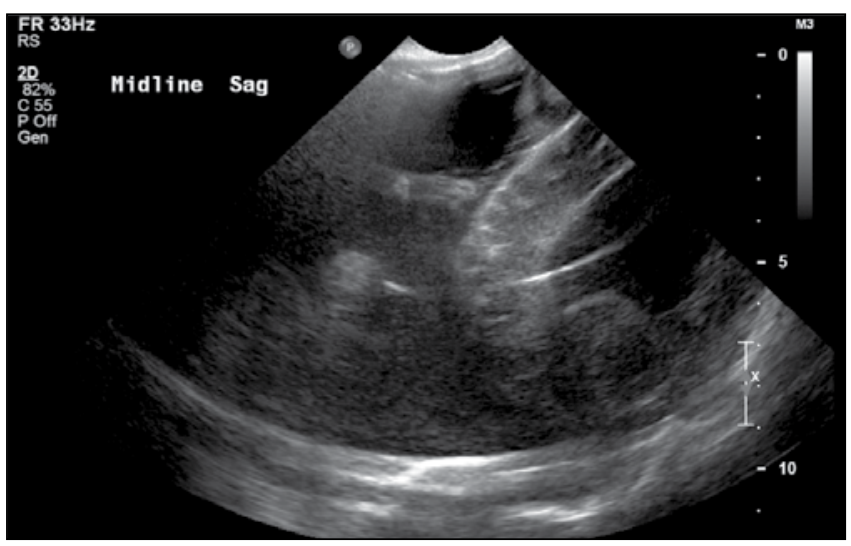

Figure 7: Sagittal midline ultrasound demonstrating the collapsed arachnoid post-operatively.

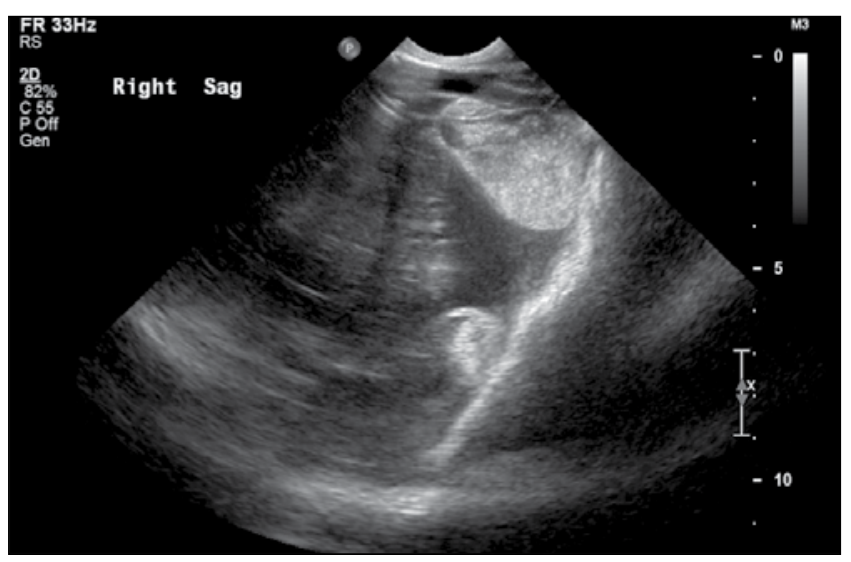

Figure 8: Coronal anterior to posterior ultrasound demonstrating the collapsed arachnoid post-operatively. 


\section{DISCUSSION}

Hydranencephaly often presents with macrocephaly (8) - including a very large cranial vault (5) - and the distinguishing radiological finding of massively enlarged, lateral ventricles that appear to be a giant cerebrospinal fluid (CSF) filled sac. This radiologic finding is characteristic of both hydranencephaly and near-hydranencephaly, which for the purpose of this report will be considered as the same (5). Near hydranencephaly has also been called maximal hydrocephalus in the literature (5). These patients can demonstrate the spectrum of hydranencephaly to maximal hydrocephalus. While some patients demonstrate a minimal yet clear layer of cortex, this case demonstrated no such findings on MRI. Several authors have suggested that EEG studies, combined with outcomes from standard treatments, could be used to precisely define the two similar conditions (9). Malheiros, et al., reports, "When hydranencephaly coexists with hydrocephalus secondary to aqueductal stenosis, it is typically accompanied by rapid enlargement of the head both in utero and after birth" (5). Clinically speaking, both conditions require immediate treatment due to the presence of both excessive head growth and increased intracranial pressure (5).

It is both the unique anatomical findings associated with hydranencephaly and the possibility of prolonged life expectancy that drives the use of ECPC in treating this condition. It is accepted by most neurosurgeons that the ultimate goal of treatment is reduction of CSF production to gain reduced intracranial pressure and reduced head size. While shunting is an option, the literature shows a trend away from this $(3,5,7,8)$. Ultimately shunts have been shown to have many complications (8) and require multiple surgeries - a significant complication in this population - which is understandably undesirable and unnecessarily expensive $(5,8)$. in a patient with no prospect of gaining neurological improvement. Albright et al. first reported that ECPC could successfully control the CSF production and thus increased intracranial pressure in patients with hydranencephaly (1). Wellons et al. also later described successful use of ECPC in treating patients with hydranencephaly (10). The significant progress that has been made in the realm of neuro-endoscopic procedures has once again placed ECPC as a primary method for treating hydrocephalus. Sandberg et al. reports a study in which the outcomes of utilizing ECPC were better than those of patients treated with shunting (8).

The use of ECPC has demonstrated the ability to manage the excessive production of CSF that characterizes the disease process hydranencephaly. The main challenge to treating hydranencephaly is the ethical question of increasing health care costs without expectations of significant improvements to quality of life. Although this report is not intended to provide a detailed ethical discussion of care for severely ill patients, it does provide some justification for the use of ECPC as compared to other methods for treating excessive CSF production. While shunting is still a viable option for these patients, some studies have reported that as many as
$81 \%$ of pediatric patients who receive a ventriculo-peritoneal (VP) shunt will require revision within 12 years (4). In addition, approximately $25-40 \%$ of pediatric patients will undergo revision in only one year (4).

A few anatomical characteristics of hydranencephaly lead to the benefits of ECPC being much greater than when utilizing ECPC in infants with other forms of hydrocephalus. First, the lack of hemispheric separation, specifically the septum pellucidum, allows for easy access to perform a bilateral ECPC (7). Secondly, the significant lack of brain parenchyma means that in these infants the choroid plexus truly is the major source of CSF, which is generally accepted to be untrue in individuals with normal brain development (8). However, it is this lack of cortex that predisposes these patients to the ECPC complication of arachnoid collapse. Regardless of the approach used to access the choroid plexus, the dural sac will be opened and thus CSF will be released. This instant change in pressure creates an immediate risk of collapse of the arachnoid both from reduced pressure within the fluid-filled sac, and also the potential space created between the dura and arachnoid. The issue of an arachnoid collapse is a significant complication in that it prevents access to the choroid plexus and can prevent access to any bleeding from vasculature within the fluid-filled sac. Ultimately, an arachnoid collapse prevents successful completion of an endoscopic approach and requires an enlarged craniotomy to allow access for a long dissection of layers and completion of the CPC. Further studies are needed to fully develop techniques to prevent arachnoid collapse. In this case the arachnoid was sutured to the dura as a preventative measure, but arachnoid collapse still occurred. The rarity of hydranencephaly precludes large prospective studies. Awareness of this potential complication can enable surgeons to both anticipate the occurrence of this complication and take steps to prevent it, such as fully securing the arachnoid to the dura at multiple locations around the entry point. Also, remaining aware of this potential complication should cause the surgeon to be conscious of the endoscope placing pressure on the edge of the dural opening. The use of profuse irrigating throughout the procedure will also work to maintain pressure within the fluid sac, which should help to prevent the arachnoid from collapsing.

Malheiros et al. concluded in their study that ECPC is a safe procedure that should be utilized in the treatment of hydranencephaly $(5,8)$. Morota et al. stated that ECPC could be the surgical treatment of choice for forms of severe hydrocephalus such as hydranencephaly (7). He further states that favorable candidates for ECPC include severely advanced hydrocephalus such as hydroanencephalic hydrocephalus and those who have a lack of or thinned out septum pellucidum to make the bilateral endoscopic coagulation possible (7). Based on the lack of previous reports of arachnoid collapse make the authors of this report confident it is a rare occurrence; yet it still remains one that should be planned for.

It is becoming nearly impossible to claim that patients with hydranencephaly cannot live for prolonged periods of time. 
Due to this prolonged survival potential, waiting to perform the ECPC until the child has further developed may reduce the risk of arachnoid collapse because of the expected increased adherence of the arachnoid to the dura. The prolonged survival presented through other studies warrants a large multi-center study to accurately determine the survival potential of patients diagnosed with hydranencephaly. Despite the outcome reported in this case, previous studies clearly demonstrate that ECPC should continue to be utilized as the preferred method of treatment for patients with hydranencephaly.

\section{REFERENCES}

1. Albright L: Percutaneous choroid plexus coagulation in hydranencephaly. Childs Brain 8:134-137, 1981

2. Barkovich MD JA, Raybaud MD C: Pediatric Neuroimaging. Lippincott: Williams \& Wilkins, 2012:808-856

3. Khalid M, Khalid S, Zaheer S, Redhu N, Ekramullah: Hydranencephaly: A rare cause of an enlarging head size in an infant. N Am J Med Sci 4:520-522, 2012

4. Lee SH, Kong DS, Seol HJ, Shin HJ: Endoscopic third ventriculostomy in patients with shunt malfunction. J Korean Neurosurg Soc 49(4): 217-221, 2011
5. Malheiros JA, Trivelato FP, Oliveira MM, Gusmao S, Cochrane DD, Steinbok P: Endoscopic choroid plexus cauterization versus ventriculoperitoneal shunt for hydranencephaly and near hydranencephaly: A prospective study. Neurosurgery 66:459-464,2010

6. McAbee GN, Chan A, Erde EL: Prolonged survival with hydrancephaly: Report of two patients and literature review. Pediatr Neurol 23:80-84,2000

7. Morota N, Fujiyama Y: Endoscopic coagulation of choroid plexus as treatment for hydrocephalus: indication and surgical technique. Childs Nerv Syst 20:816-820, 2004

8. Sandberg DI, Chamiraju P, Zoeller G, Bhatia S, Ragheb J: Endoscopic choroid plexus coagulation in infants with hydranencephaly or hydrocephalus with a minimal cortical mantle. Pediatr Neurosurg 48:6-12, 2012

9. Sutton LN, Bruce DA, Schut L: Hydranencephaly versus maximal hydrocephalus: An important clinical distinction. Neurosurgery 6:34-38,1980

10. Wellons JC III, Tubbs RS, Leveque JCA, Blount JP, Oakes WJ: Choroid plexectomy reduced neurosurgical intervention in patients with hydroanencephaly. Pediatr Neurosurg 36:148152,2002 